\title{
Hashimoto's thyroiditis and polyarthritis: a possible subset of seronegative polyarthritis
}

\author{
NICOLE G. H. LeRICHE* AND DAVID A. BELL \\ From University Hospital, Rheumatic Diseases Unit, Department of Medicine, University of Western Ontario, \\ London, Ontario, Canada
}

SUMMARY Fifteen patients presenting with inflammatory polyarthritis who had Hashimoto's thyroiditis were investigated. Only $2 / 15$ had frank myxoedema, $8 / 15$ had incipient hypothyroidism (raised levels of thyrotropin or early symptoms of mild hypothyroidism), and $5 / 15$ were euthyroid (thyrotropin levels normal). The presence or absence of rheumatoid factor (RF) distinguished two subgroups with different severity of synovitis. Nine out of 15 (group A) who remained RF negative throughout their follow-up had mild polyarthritis, lacked nodules or erosions on $x$-ray, and required, in addition to thyroid replacement, non-steroidal antiinflammatory drugs for control of synovitis. Six out of 15 who remained RF positive (group B) had more severe synovitis, nodules, and erosive $x$-ray changes, and some required remittive drug treatment to control their disease. HLA-DR2 was present in $67 \%$ of group A and $13 \%$ of group B patients, while HLA-DR4 was present in $67 \%$ of group B and $33 \%$ of group A. Group A patients may represent a subset of patients with Hashimoto's thyroiditis and seronegative inflammatory polyarthritis, while group B patients appear to have features suggesting the coexistence of both rheumatoid arthritis and Hashimoto's thyroiditis.

Hashimoto's thyroiditis (HT) is considered an autoimmune disease whose detection was originally based on tissue biopsy but which now can be reliably detected by the presence of high titre antimicrosomal antibodies. ${ }^{12}$ Its relationship to rheumatic diseases seems more frequent than might be expected, but this has not been definitely proved..$^{3-8}$ Hashimoto's thyroiditis frequently leads to hypothyroidism, which in turn can progress to myxoedema. Rheumatic syndromes associated with hypothyroidism include fibrositis, myositis, myalgias, carpal tunnel syndrome, Sjögren's syndrome, joint stiffness, and joint effusion. ${ }^{8-15}$ Most of these manifestations are said to resolve with adequate thyroid replacement. Among a group of patients described by Bland and Frymoyer ${ }^{14}$ with hypothyroidism and an arthropathy resembling RA, which responded to thyroid replacement alone, morning stiffness was absent, and the involved joints were

Accepted for publication 20 January 1984.

Correspondence to Dr David A. Bell, Rm 40F4, University Hospital, Box 5339, Stn A, London, Ontario, Canada N6A 5A5. 'Present address, National Institutes of Health, Bethesda, Maryland, USA. said not to be tender and to lack other signs of inflammation.

We have encountered a small group of patients presenting with inflammatory polyarthritis (IP) who were found to have Hashimoto's thyroiditis in the course of investigation. In contrast to previous reports of the arthropathy associated with hypothyroidism most of the patients we studied had little or no evidence of hypothyroidism at presentation. These patients were evaluated further in order to attempt to determine the relationship between their inflammatory thyroid disorder and polyarthritis. The results of an initial and follow-up clinical and serological assessment of these patients forms the basis of the present report.

\section{Patients and methods}

Fifteen Caucasian patients were studied, of whom one was male. Their average age was 50.3 years (range 23-71 years). They presented initially in the Rheumatology Outpatient Clinic at University Hospital, where they had been referred from 1975 to 1982 for assessment of polyarthritis by one of us (D.A.B.). Inclusion in the study group was based on 
the presence of IP (pain, swelling, and tenderness in more than four joints) and the finding of HT in the course of investigation. The average age at presentation was 50 years (range 23-71), and the average duration of polyarthritis, when first seen, was $3 \cdot 1$ years (range 6 months to 10 years).

Twelve of the 15 patients fulfilled ARA criteria ${ }^{16}$ for 'definite' or 'classical' rheumatoid arthritis, and, of these, four had some additional clinical features of systemic lupus erythematosus. Of these four patients with 'overlap' only one could be correctly classified as having systemic lupus erythematosus according to ARA criteria. ${ }^{17}$ Three of the 15 patients had 'probable rheumatoid arthritis' according to ARA criteria, and, of these, one had some SLE features. No patient with clear evidence of gout, pseudogout, scleroderma, spondylarthritis, or primary osteoarthritis was included. Criteria for HT included presence of: high titre antimicrosomal antibody $^{1}$ (ATM, titre $>1 / 400$ present among all patients); increased thyroidal tissue; and, in patients not receiving thyroid replacement, elevation of thyroid stimulating hormone (TSH). All patients had high titre ATM and all but three patients had had increased TSH initially or at some time during the follow-up period. Eight patients had enlarged thyroid glands.

Initial and follow-up clinical assessments of the patients were made, the treatment given was recorded, and Schirmer testing was performed to detect keratitis sicca (abnormal value $<5 \mathrm{~mm}$ wetting in $5 \mathrm{~min}$ ).

Laboratory assessment. Laboratory assessment included tests of thyroid function $\left(\mathrm{T}_{3}\right.$ (resin uptake), $\mathrm{T}_{4}$ RIA (total), $\mathrm{T}_{3}$ RIA (total)), and TSH. Quantitative immunoglobulins (determined by nephelometry, Hyland system), total haemolytic complement and $\mathrm{C} 1 \mathrm{q}$ binding, ${ }^{18}$ rheumatoid factor (RF), ${ }^{19}$ antinuclear antibody (ANA), ${ }^{20}$ antibody to nRNP and Sm, ${ }^{21}$ anti-Ro (SS-A), anti-La (SS-B), ${ }^{22}$ antithyroglobulin and antimicrosomal antibodies (AMES microtitre). A modified Farr assay was used to detect anti-DNA antibody. ${ }^{24} \mathrm{~A}$ reverse haemolytic plaque forming assay was employed to detect spontaneous synthesis of total immunoglobulins in vivo from non-cultured nylon wool enriched circulating B lymphocytes according to previously described methods. ${ }^{25}$ All cells were plaqued within two hours of collection and were cyclohexamide inhibitable. HLA typing for A, B, C, DR antigens was performed by a microcytoxicity assay employing Terasaki typing reagents. ${ }^{26}$ HLA-DR typing employed nylon wool purified peripheral blood B lymphocytes and Terasaki Typing Tray 12 . Hand radiographs were read blindly and independently for characteristic evidence of rheumatoid arthritis or other abnormalities such as chondrocalcinosis or osteoarthritis.

\section{Results}

CLINICAL AND LABORATORY FEATURES

At initial assessment an average of 13 active (tender and/or swollen) joints per patient were noted compared with an average of 8 active joints per patient at follow-up assessment. The inflammatory polyarthritis was generally symmetrical, involving four or more joints, and often the small joints of the hands and feet accompanied by swelling, pain, and tenderness.

Since most patients had relatively recent onset of polyarthritis, and this was accompanied by mild or incipient hypothyroidism, we assume these events were relatively close in onset. Only two of the 15 patients presented with clinical evidence of obvious hypothyroidism. Eight patients presented with 'incipient' hypothyroidism and had very mild clinical features such as cold intolerance, fatigue, raised TSH but normal thyroid function tests. Two of the 15 patients had developed hypothyroidism following treatment with radioactive iodine for Graves' disease, and were receiving adequate thyroid replacement when first evaluated with IP. They had serological evidence of HT and were rheumatoid factor positive. Two patients with a normal TSH at presentation with IP developed a raised TSH during the course of follow-up and were then treated with exogenous thyroid hormone. Two of the 15 patients were euthyroid initially and have remained so despite continued thyroid enlargement and an elevated antithyroid antibody level in one.

The presence or absence of rheumatoid factor

Table 1 Clinical features of patients at follow-up

\begin{tabular}{|c|c|c|}
\hline & $\begin{array}{l}\text { Group } A \\
(R F-v e)(n=9)\end{array}$ & $\begin{array}{l}\text { Group B } \\
(R F+v e)(n=6)\end{array}$ \\
\hline $\begin{array}{l}\text { Average age, years } \\
\text { (range) }\end{array}$ & $54(23-71)$ & $54(34-68)$ \\
\hline $\begin{array}{l}\text { Average duration of } \\
\text { inflammatory } \\
\text { polyarthritis, years } \\
\text { (range) }\end{array}$ & $4.9(1-11)$ & $4 \cdot 8(1-14)$ \\
\hline $\begin{array}{l}\text { Average duration of } \\
\text { follow up, years (range) }\end{array}$ & $2 \cdot 8(1 \cdot 5-8)$ & $3.5(1 \cdot 5-8)$ \\
\hline $\begin{array}{l}\text { Average joint count per } \\
\text { patient (range) } \\
\text { Number of patients with: }\end{array}$ & $5 \cdot 6(0-14)$ & $12 \cdot 5(3-40)$ \\
\hline Thyroid enlargement & 5 & 3 \\
\hline Sjögren's syndrome & 3 & 2 \\
\hline Rheumatoid nodules & 0 & 4 \\
\hline $\begin{array}{l}\text { Erosions on hand } \\
\text { radiographs }\end{array}$ & 0 & 3 \\
\hline
\end{tabular}

$\mathrm{RF}=$ rheumatoid factor. 
permitted subdivision of these 15 patients into two groups. The rheumatoid factor status of these two groups persisted throughout the follow-up period. Their clinical features are summarised in Table 1. The only distinguishing features between these two groups were the presence of more active joints, rheumatoid nodules, and erosions among the rheumatoid factor positive group.

Five out of 15 patients had some clinical and laboratory features suggesting SLE. Only one of these (case 6, Table 2) had sufficient criteria for a definite diagnosis of SLE. In the others photosensitivity was common (4/5), while other features present include alopecia (2/5), Raynaud's phenomenon (2/5), and a history of pleurisy (2/5). None had major organ involvement. Two had positive LE cells, two had low level anti-DNA antibody $(<50$ binding), and 1 had anti-nRNP. None had anti-Sm, anti-Ro (SS-A), or anti-La (SS-B) antibody.

A summary of the individual features of each patient in these separate groups is shown in Table 3, together with the results of HLA typing. No increase in any HLA $A, B$ or C antigens was detected (data not shown). HLA-DR2 occurred in 6/9 group A patients but only in $1 / 6$ group B patients. In contrast HLA-DR4 was present in $4 / 6$ group B patients and only 3/9 group A patients. These numbers were too small to permit any statistical comparison.

The total number of circulating spontaneous immunoglobulin plaque forming cells (CSIPFC) was increased in most patients studied, although this was

Table 2 Clinical and laboratory features

\begin{tabular}{|c|c|c|c|c|c|c|c|c|c|}
\hline & \multicolumn{2}{|c|}{ Features of } & \multirow{2}{*}{$\begin{array}{l}\text { Thyroid } \\
\text { size }\end{array}$} & \multirow[t]{2}{*}{$A N A$} & \multicolumn{2}{|l|}{ Titre $A T M^{*}$} & \multicolumn{2}{|l|}{$T S H^{+}$} & \multirow{2}{*}{$\begin{array}{l}H L A-D R \\
\text { antigens }\end{array}$} \\
\hline & $S L E$ & Sjögren's & & & Initial & Follow-up & Initial & Follow-up & \\
\hline \multicolumn{10}{|c|}{ Group A (RF-) } \\
\hline 1 & - & + & + & + & $1 / 1600$ & $1 / 1600$ & $\mathbf{N}$ & $\mathbf{N}$ & 2,5 \\
\hline 2 & - & - & - & - & $1 / 1600$ & $1 / 1600$ & $\uparrow$ & $\uparrow$ & 2,4 \\
\hline 3 & - & - & - & - & $1 / 25600$ & $1 / 25600$ & $\uparrow$ & $\mathbf{N}$ & 2,5 \\
\hline 4 & - & - & - & - & $1 / 6400$ & $1 / 6400$ & $\mathbf{N}$ & $\uparrow$ & 2,1 \\
\hline 5 & - & + & - & + & $1 / 1638000$ & $1 / 409600$ & $\uparrow$ & $\mathbf{N}$ & 2,4 \\
\hline 6 & + & + & + & + & $1 / 25600$ & $1 / 1600$ & $\uparrow$ & $\mathbf{N}$ & $3,6 \mathrm{Y}$ \\
\hline 7 & + & - & + & + & $1 / 6400$ & $1 / 25600$ & $\uparrow$ & $\mathbf{N}$ & $4,-$ \\
\hline 8 & + & - & + & - & $1 / 6400$ & $1 / 1600$ & $\uparrow$ & $\mathbf{N}$ & $3,6 \mathrm{Y}$ \\
\hline 9 & + & - & + & - & $1 / 1600$ & $1 / 25600$ & $\mathbf{N}$ & $\uparrow$ & 2,7 \\
\hline \multicolumn{10}{|c|}{ Group B (RF+) } \\
\hline 10 & - & + & + & + & $1 / 400$ & $1 / 100$ & $\mathbf{N}$ & $\mathbf{N}$ & 4,7 \\
\hline 11 & - & - & - & + & $1 / 1638400$ & $1 / 6400$ & $\uparrow$ & $\mathbf{N}$ & 4,7 \\
\hline 12 & + & - & - & + & $1 / 400$ & $1 / 400$ & $\uparrow$ & $\uparrow$ & 2,7 \\
\hline 13 & - & - & + & + & $1 / 102400$ & $1 / 25600$ & $\uparrow$ & $\mathbf{N}$ & 3,4 \\
\hline 14 & - & - & - & - & $1 / 1600$ & $1 / 400$ & $\mathbf{N}$ & $\mathbf{N}$ & 4,5 \\
\hline 15 & - & - & + & - & $1 / 25600$ & $1 / 25600$ & $\uparrow$ & $\mathrm{N}$ & 1,5 \\
\hline
\end{tabular}

ATM: antithyroid microsomal antibody titre in serum.

'TSH: $\mathrm{N}=<10 \mathrm{mU} / \mathrm{l} ; \uparrow=>10 \mathrm{mU} / \mathrm{l}$.

Table 3 Correlation of antithyroid antibody, serum immunoglobulins, and circulating polyclonally activated $B$ lymphocytes

\begin{tabular}{|c|c|c|c|c|c|}
\hline Clinical group & No. & $P F C / 10^{6 \S}$ & $\lg (m g)^{\|}$ & $\begin{array}{l}\% \text { Positive for } \\
\text { antithyroid }\end{array}$ & $\begin{array}{l}\text { Rheumatoid } \\
\text { factor }\end{array}$ \\
\hline Thyroiditis A & 9 & $1888(880-4206)$ & $1866(1142-2754)$ & 100 & 0 \\
\hline Thyroiditis B & 6 & $2929(946-5464)$ & $1481(1008-1678)$ & 100 & 100 \\
\hline RA (EAF) $1^{*}$ & 13 & $3000(1310-7920)$ & $1909(1194-3106)$ & 0 & 100 \\
\hline RA (no EAF) $11^{\dagger}$ & 11 & $560(50-885)$ & $1819(1009-1824)$ & 0 & 100 \\
\hline Normal Controls ${ }^{\ddagger}$ & (9) & $300-900$ & 2006 & 0 & 0 \\
\hline
\end{tabular}

Thirteen RA patients with nodules and other extra-articular features (EAF).

${ }^{\dagger}$ Eleven RA patients with no evidence of extra-articular features (EAF).

${ }^{\ddagger}$ Healthy normal controls.

Mean number of total immunoglobulin plaque forming cells $(\mathrm{IgG}+\operatorname{IgA}+\operatorname{IgM})$ per million non-cultured circulating

B cells in vivo (range).

"Mean serum total (IgG + IgA + IgM) immunoglobulin levels (range). 
not usually reflected in increased serum Ig levels. Patients in group B who had both antithyroid autoantibodies and rheumatoid factor had the highest levels of CSIPFC. Increased levels of CSIPFC were also seen in a different group of 13 patients with definite rheumatoid arthritis with associated nodules and vasculitis, but no thyroid abnormalities. Despite the suggestion of polyclonal B cell activation in the form of increased levels of CSIPFC, none of these patients with RA and extraarticular features had detectable thyroid autoantibodies.

\section{RESPONSE TO TREATMENT}

Non-steroidal anti-inflammatory drugs (NSAID) were initially required by most $(14 / 15)$ patients and at follow-up (6/8 group $A$ and $6 / 6$ group $B)$, while corticosteroids in low doses $(6 / 15)$ or remittive agents such as gold or antimalarials (3/15), used at a similar frequency in both groups, were seldom required. There was no consistent relationship between restoration of normal thyroid function (restoration of TSH to normal) and improvement in polyarthritis, and in several group A patients inflammatory polyarthritis preceded any evidence of abnormal thyroid function.

\section{Discussion}

This study, which describes a group of patients with inflammatory joint disease and Hashimoto's thyroiditis, adds another dimension to the association between thyroid disorders and abnormalities of the musculoskeletal system. Included in the spectrum of thyroid disorders and associated musculoskeletal dysfunction are the fibrositis syndrome ${ }^{10}$ myositis ${ }^{13}$ and/or myopathy, Sjögren's syndrome, ${ }^{15}$ and the non-inflammatory joint effusions in patients with frank hypothyroidism described by Bland and Frymoyer. ${ }^{14}$ The patients we report here, however, appear to differ from those described by Bland and Frymoyer, since our patients had inflammatory polyarthritis (joint stiffness, tenderness, and effusion), which did not, in those patients who were also hypothyroid, resolve with thy, oid replacement. Thus the polyarthritis in our patients seemed more related to the inflammatory and serological features of Hashimoto's thyroiditis than to its resultant hypothyroidism, since the associated hypothyroidism was usually only mild, thyroid replacement did not 'cure' the polyarthritis, and in two patients polyarthritis and thyroiditis preceded biochemical evidence of hypothyroidism (increase in TSH).

Two major groups of patients with Hashimoto's thyroiditis and inflammatory polyarthritis were encountered, including one group (A) with persistently rheumatoid factor negative polyarthritis ( $a$ few patients also had incompletely expressed SLE but were usually ANA negative) and a second group (B) who were persistently rheumatoid factor positive and more closely resembled patients with RA (nodules and erosions were also occasionally present). Thus group B patients may have RA with coincidental Hashimoto's thyroiditis, a conclusion that accords with their increased frequency of HLA-DR4 characteristically seen in seropositive RA. ${ }^{27}$ Most group A patients in contrast had HLA-DR2 but seldom HLA-DR4, adding to the notion that these patients with seronegative polyarthritis may represent a different syndrome with a different pathogenesis and clinical course.

The present studies offer no explanation for the coexistence of thyroiditis and polyarthritis. The occurrence of both thyroiditis and 'rheumatoid arthritis' has been frequently cited as an example of Berkson's bias resulting from overascertainment of two disorders occurring together by chance. The manner of selection of these patients could lead to this type of interpretation. These studies however suggest that the persistently rheumatoid factor negative group A patients may represent a distinctive syndrome or subset of seronegative polyarthritis different than rheumatoid arthritis. The existence in this group of patients of increased numbers of circulating activated $B$ cells, a feature hitherto seen only among rheumatoid factor positive RA patients with extraarticular features such as vasculitis and/or nodules, ${ }^{28}$ suggests the possible influence by the inflammatory thyroid lesion among these patients. In some patients antithyroid autoantibodies could be injurious to synovial tissue, and as suggested by Blake and co-workers ${ }^{29}$ the synovial tissue itself may contain a repository of antithyroid antibody forming cells. These could traffic to the thyroid gland and lead to tissue damage. The synovitis is probably due to factors additional to antithyroid autoantibodies, since many patients with Hashimoto's thyroiditis do not develop detectable synovitis.

The authors wish to thank Ron Komar and Dr W. B. Chodirker for performing the serological assays on these patients, and our colleagues Drs M. Harth and B. Wolfe for permitting us to examine some of their patients. We also thank Mrs M. French for preparing the manuscript.

\section{References}

1 Doniach D, Bottazzo G F, Russell R C G. Goitrous autoimmune thyroiditis (Hashimoto's disease). Clin Endocrinol (Oxf) 1979; 8: 63-80.

2 Roitt I M, Doniach D, Campbell P N, et al. Autoantibodies in Hashimoto's disease (lymphadenoid goitre). Lancet 1956; ii: 820-2.

3 Gertner E, Russell M L, Vale J. Rheumatoid arthritis (RA) and thyroid disease. Arthritis Rheum 1981; 24 (supple): S99. 
4 Buchanan W W, Crooks J, Alexander W D, et al. Association of Hashimoto's thyroiditis in rheumatoid arthritis. Lancet 1961; i: $245-8$.

5 Linos A, Worthington J W, Palumbo P J, et al. Occurrence of Hashimoto's thyroiditis and diabetes mellitus in patients with rheumatoid arthritis. J Chron Dis 1980; 33: 73-7.

6 Becker K L, Ferguson R H, McConahey W M. The connective tissue diseases and symptoms associated with Hashimoto's thyroiditis. $N$ Engl $J$ Med 1963; 268: 277-80.

7 Mulhern L M, Masi A T, Shulman L E. Hashimoto's disease - a search for associated disorders in 170 clinically detected cases. Lancet 1966; ii: 508-12.

8 Bland $\mathrm{J} \mathrm{H}$, Frymoyer $\mathrm{J} \mathrm{W}$, Newberg A H, et al. Rheumatic syndromes in endocrine disease. Semin Arthritis Rheum 1979; 9: 23-65.

9 Delamere J P, Scott D L, Felix-Davies D D. Thyroid dysfunction and rheumatic diseases. $J R$ Soc Med 1982; 75: 102-6.

10 Wilke W S, Sheeler L R, Makerkowski W S. Hypothyroidism with presenting symptoms of fibrositis. J Rheumatol 1981; 8: 626-31.

11 Frymoyer J W, Bland J H. Carpal tunnel syndrome in patients with myxedematous arthropathy. J Bone Joint Surg 1973; 55A: 78-82.

12 Golding D N. Hypothyroidism presenting with musculoskeletal symptoms. Ann Rheum Dis 1970; 29: 10-4.

13 Hochberg M C, Koppes G M, Edwards C G, et al. Hypothyroidism presenting as a polymyositis like syndrome. Arthritis Rheum 1979; 19: 1363-6.

14 Bland J H, Frymoyer J W. Rheumatic syndromes of myxedema. $N$ Engl J Med 1970; 282: 1171-4.

15 Karsh J, Pavlidis N, Weintraub B D, et al. Thyroid disease in Sjögren's syndrome. Arthritis Rheum 1980; 23: 1326-9.

16 Ropes M W, Bennett E A, Cobb S, et al. Revision of diagnostic criteria for rheumatoid arthritis. Bull Rheum Dis 1958; 9: 275.

17 Tan E M, Cohen A S, Fries J F, et al. The 1982 revised criteria for the classification of systemic lupus erythematosus. Arthritis Rheum 1982; 25: 1271-7.

18 Zurier $\mathrm{R}$ H, Lambert $\mathrm{PH}$. In vitro methods in cell mediated and tumour immunity. London: Academic Press, 1976: 565-72.

19 Singer $\mathbf{J}$ M and Plotz C M. The latex fixation test I. Application to the serologic diagnosis of rheumatoid arthritis. Am J Med 1956; 21: 888-92.

20 Barnett E V, Cordemi J J, Leddy J P, et al. Gamma 2, gamma $1 \mathrm{~A}$ and gamma $1 \mathrm{M}$ antinuclear factors in human sera. $J$ Clin Invest 1964; 43: 1104-15.

21 Bresnihan B, Bunn C. Snaith M L, et al. Antiribonucleoprotein antibodies in connective tissue diseases: estimation by counterimmunoelectrophoresis. Br Med J 1977; i: 610-1.

22 Clark G, Reichlin M, Tomasi T D. Characterization of a soluble cytoplasmic antigen reactive with sera from patients with systemic lupus erythematosus. $J$ Immunol 1968; 102: 117-22.

23 Mattioli M. Reichlin M. Characterization of a soluble nuclear ribonucleoprotein antigen reactive with SLE sera. J Immunol 1971; 197: 1281-90.

24 Pincus T. Immunochemical conditions affecting the measurement of DNA antibodies using ammonium sulfate precipitation. Arthritis Rheum 1971; 14: 623-30.

25 Bellamy N, Cairns E, Bell D A. Immunoregulation in rheumatoid arthritis: evaluation of T lymphocyte function in the control of polyclonal immunoglobulin synthesis in vitro. $J$ Rheumatol 1983; 10: 19-27.

26 Terasaki P I, Bernoco D, Park M S, et al. Microdroplet testing for HLA A, B, C. D antigens. Am J Clin Pathol 1978; 69: 103-20.

27 Stastny P. Association of the B cell alloantigen DRW4 with rheumatoid arthritis. N Engl J Med 1978; 298: 869-71.

28 Bell D A, Pinto J. Distribution of activated B lymphocytes in the circulation and synovial fluid in rheumatoid arthritis. Clin Immunol Immunopathol in press.

29 Blake D R, Stansfield E, McGregor A M. Rees Smith B. Antithyroid antibody activity in the synovial fluid of patients with various arthritides. Lancet 1979; ii: 224-6. 